\title{
УТИЛИЗАЦИЯ БАЛЛАСТНОЙ ПОПУТНО ДОБЫВАЕМОЙ ВОДЫ С ПРИМЕНЕНИЕМ ТЕХНОЛОГИИ СКВАЖИННОЙ СЕПАРАЦИИ ВОДОНЕФТЯНЫХ ЭМУЛЬСИЙ
}

\author{
Лекомцев Александр Викторович1, \\ alex.lekomtsev@mail.ru
}

\author{
Дерендяев Константин Алексеевич1, \\ k.derendyaev@yandex.ru
}

Бурцев Андрей Сергеевич 1 , andrey.burtsev97@gmail.com

\section{Степаненко Иван Борисович1, stepanenk02403@gmail.com}

\author{
Жигарев Даниил Борисович 1 , \\ zhigarev.daniil@mail.ru \\ 1 Пермский национальный исследовательский политехнический университет, \\ Россия, 614990, г. Пермь, пр. Комсомольский, 29.
}

\begin{abstract}
Актуальность. Одной из основных проблем нефтедобывающей промышленности в сфрере добычи нефти и газа является добыча больших объемов балластной воды. Средняя кратность перекачиваемой воды к нефти может составлять 4:1 и более. На территории Пермского края данная проблема является особенно актуальной, так как многие месторождения находятся на 3 и 4 стадиях разработки и требуют внедрения новых технологий для более рентабельной добычи нефти. В связи с перекачкой больших объемов жидкости происходит более быстрый процесс износа оборудования и появляются дополнительные затраты электроэнергии для его использования. В связи с этим внедрение технологии скважинной и кустовой сепарации водонефртяной эмульсии является одним из наиболее эфффективных способов решения производственной задачи путем децентрализации системы сбора и подготовки скважинной продукции.

Цель: уменьшение затрат на сбор и подготовку скважинной продукции путем применения технологии кустовой сепарации водонефтяной эмульсии при децентрализованной системе подготовки.

Объект: кусты скважин со средней обводненностью 65-70 \% и более.

Mетоды: обзор научной литературы, моделирование процесса кустовой сепарации в Aspen HYSYS; лабораторные исследования на созданном макете, имитирующем скважину.

Результаты. Представлена технология кустового разделения продукции скважин на нефрть и воду с дальнейшим использованием попутно добываемой воды в системе поддержания пластового давления. Представлена принципиальная технологическая схема установки. Проведены лабораторные испьтания, выявлены оптимальные параметры её работы. Приведена технико-экономическое оценка реализации технологии и обоснованные технические решения.
\end{abstract}

Ключевые слова:

Подготовка скважинной продукции, скважинная сепарация, балластная вода, водонефтяная эмульсия, сброс воды.

\section{Введение}

Высокие давления в трубопроводах системы сбора и транспортировки скважинной жидкости приводят к увеличению энергопотребления глубинного и наземного насосного оборудования и повышают риск выхода его из строя. Это обусловлено образованием высоковязкой обратной нефтяной эмульсии и отложением твердых органических и неорганических солей в трубопроводах. Помимо этого, большое количество скважин добывает высокообводненную продукцию, что существенно увеличивает эксплуатационные затраты на сбор, транспорт и подготовку сырой нефти, а также на возврат попутно добываемой воды до нагнетательных скважин [1, 2]. На 40 \% месторождений, территориально расположенных в Пермском крае, существуют обозначенные проблемы. В этой связи актуальным становится вопрос подготовки скважинной продукции на кустовой площадке с целью снижения давления в трубопроводе, вероятности образования пробок, уменышения загрузки промысловых объектов подготовки, снижения затрат на транспорт и разделение водонефтяной эмульсии (ВНЭ), а также на перекачку воды в системах сбора продукции скважин и поддержания пластового давления (ППД).

В ходе анализа отечественной и зарубежной литературы и патентной документации установлено, что технология кустовой сепарации хорошо изучена и используется с применением различных методов разделения водонефтяной эмульсии, но при этом требует доработок и устранений имеющихся недостатков [3-13].

На основании анализа научной литературы выделены технические решения, позволяющие обеспечивать сепарацию попутно добываемой воды на кустовых площадках скважин [14-20]. В качестве водоотделителя планируется использовать скважину в консервации.

В статье предлагается применение технологии кустовой сепарации с целью снижения операционных расходов на сбор, транспортировку и подготовку нефти, газа и воды. На рис. 1 представлена принципиальная схема сбора и подготовки скважинной продукции с применением технологии кустовой сепарации. 


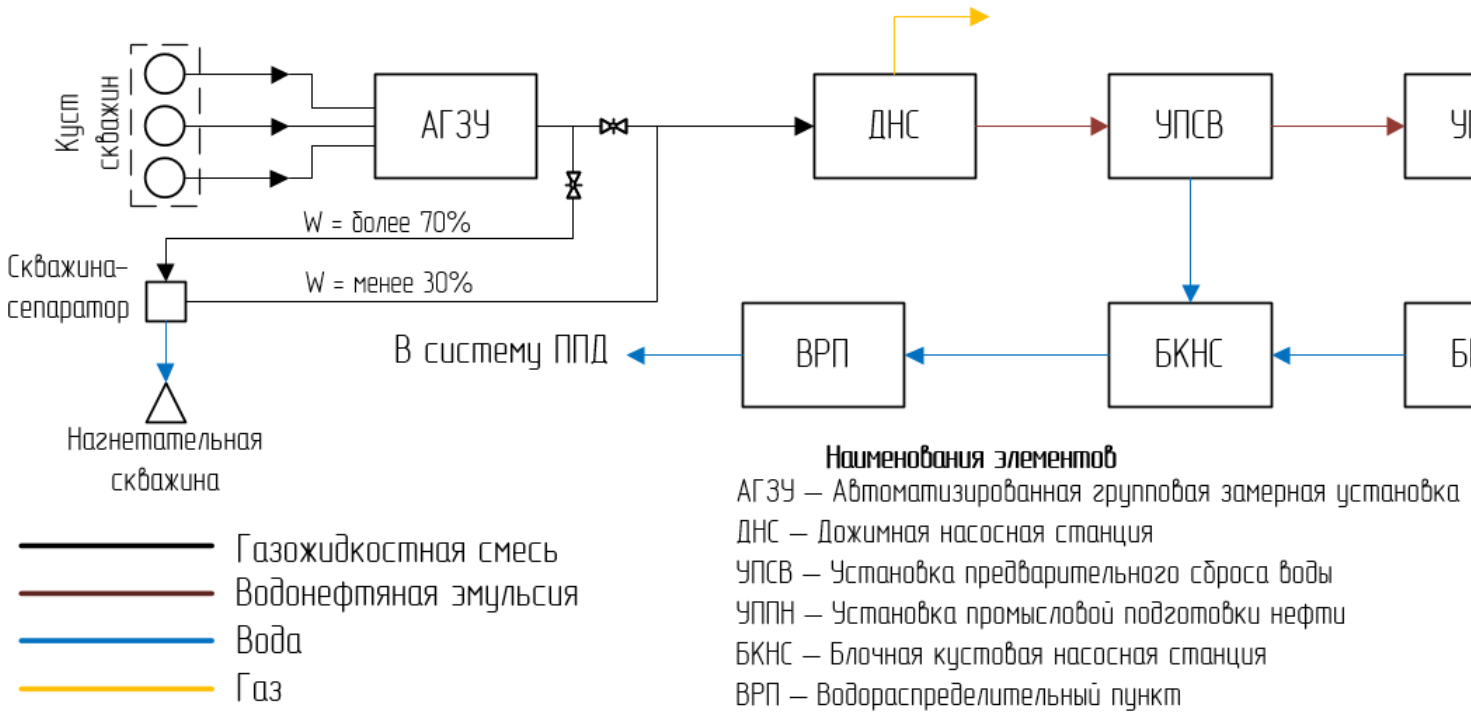

Рис. 1. Принципиальная схема сбора и подготовки с реализацией кустовой сепарации

Fig. 1. Scheme of collection and preparation with implementation of cluster separation

С кустовой площадки высокообводненная эмульсия (с содержанием воды более 70 \%) проходит через измерительные устройства и далее поступает в скважину-сепаратор, где происходит процесс сброса свободной попутной воды. Жидкость с существенно меньшей обводненностью (менее $30 \%$ ) поступает в общую систему сбора. Отделенная вода направляется в нагнетательную скважину. По технологии имеется возможность направить всю добытую жидкость в общую систему сбора для осуществления технического обслуживания скважины-сепаратора.

\section{Технология процесса}

Технология децентрализованной подготовки скважинной продукции позволяет обеспечить предварительный сброс некоторого количества попутно добываемой воды, тем самым существенно снизить износ используемого оборудования, эксплуатационные затраты, а также линейные давления в скважинах. Для достижения большей эффективности технологии рекомендуется использовать ее для кустов скважин с обводненностью 75 \% и более.

Данная разработка дает возможность разделять продукцию добывающих скважин. При этом отделившаяся вода направляется для нужд ППД, а частично обезвоженная нефть возвращается обратно в технологический процесс. В качестве сепаратора используется скважина в консервации. Принципиальная технологическая схема скважинной сепарации продукции представлена на рис. 2.

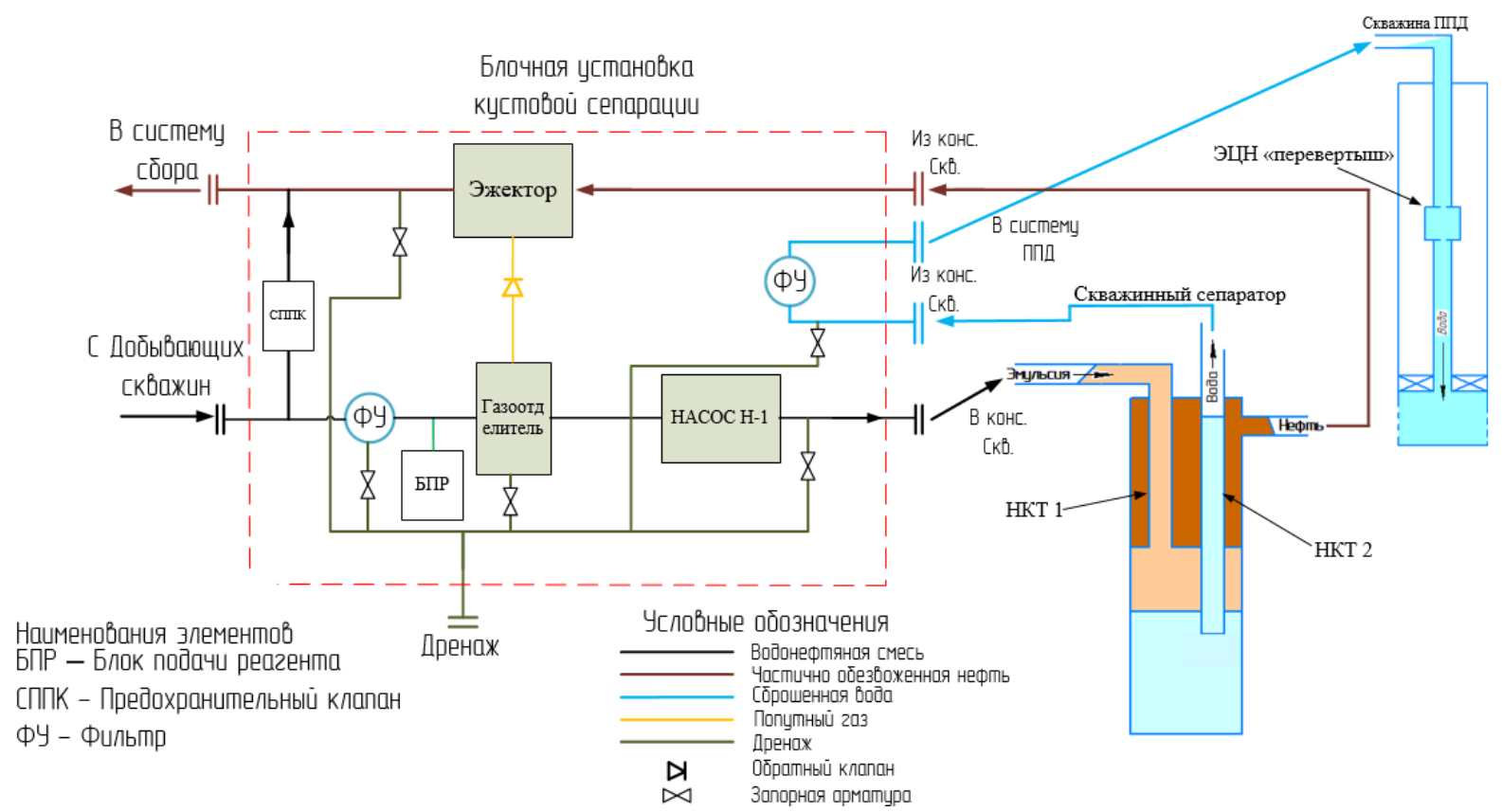

Рис. 2. Принципиальная технологическая схема скважинной сепараџии

Fig. 2. Principal technological scheme of borehole separation 
Установка кустовой сепарации работает следующим образом. Скважинная продукция со сборного коллектора или с автоматизированной групповой замерной установки (АГЗУ) по трубопроводу через газоотделитель направляется на вход прием насоса $\mathrm{H}-1$, который нагнетает давление в трубопроводе и транспортирует ВНЭ в скважину-сепаратор. Частично обезвоженная нефть, скопившаяся в верхней части скважины, из затрубного пространства самотеком поступает либо на вход эжектора, либо через байпас в систему сбора. Отделившаяся вода под давлением, создаваемым насосом $\mathrm{H}-1$, по НКТ направляется на фильтр тонкой очистки для снижения содержания нефтепродуктов и твердых примесей. Далее по трубопроводу отфильтрованная вода направляется в нагнетательную скважину системы ППД [21].

В связи с высоким значением газового фактора добывающих скважин возникает риск вредного влияния на работу скважинного сепаратора. При средней обводненности $90 \%$ наблюдается повышенное удельное содержание свободного газа, которое может достигать $26 \%$ по объему. Основными осложняющими факторами являются:

a) скопление газа в виде газовой шапки в первой лифтовой трубе; b) поступление газа на прием насоса;

c) интенсивное перемешивание эмульсии.

Для отделения газа и улучшения процесса разделения в скважине-сепараторе перед входом установлен газоотделитель. Выделившийся попутный газ поступает на прием эжектора как пассивная фаза, в которой частично обезвоженная эмульсия (активная фаза) за счет конструктивных особенностей работы всасывает низконапорный поток, и в результате их смешивания образуется газожидкостная смесь.

Отделившаяся в скважине-сепараторе вода должна соответствовать стандартам предприятия (СТП) и быть не хуже показателей качества вод по содержанию нефтепродуктов и твердых взвешенных частиц (ТВЧ) для закачки в пласт. Содержание примесей будет регулироваться расходом электроцентробежного насоса (ЭЦН), для определения оптимального расхода требуется проводить дополнительные расчеты.

\section{Выбор оптимального куста скважин}

На основании проведенного анализа из 209 потенциальных объектов на 20 месторождениях, подходящих по условиям внедрения технологии, выбран куст со скважинами 1-3. Основные технологические параметры работы скважин приведены в табл. 1.

Таблица 1. Технологические параметры добывающих скважин

Table 1. Technological parameters of producing wells

\begin{tabular}{|c|c|c|c|c|c|c|c|c|c|}
\hline $\begin{array}{l}\text { Скв. } \\
\text { Well }\end{array}$ & $\begin{array}{c}\text { Пласт } \\
\text { Reservoir }\end{array}$ & $\begin{array}{l}\mathrm{P}_{\text {лин }}, \\
\mathrm{MПа} \\
\mathrm{P}_{\text {line }}, \\
\mathrm{MПа}\end{array}$ & $\begin{array}{c}\mathrm{Q}_{\text {ж }} \\
\mathrm{m}^{3} / \mathrm{cyT} \\
\mathrm{Q}_{\mathrm{liq}} \\
\mathrm{m}^{3} / \mathrm{d} \\
\end{array}$ & $\begin{array}{c}\% \text { воды } \\
\% \text { of } \\
\text { water }\end{array}$ & 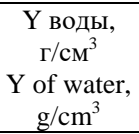 & 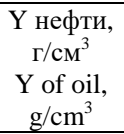 & 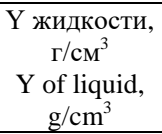 & $\begin{array}{c}\mathrm{Q}_{\mathrm{H}}, \\
\mathrm{T} / \mathrm{cyT} \\
\mathrm{Q}_{\text {oil }}, \mathrm{t} / \mathrm{d}\end{array}$ & $\begin{array}{c}\text { Газовый фактор, } \\
\mathrm{m}^{3} / \mathrm{T} \\
\text { Gas factor, } \mathrm{m}^{3} / \mathrm{t}\end{array}$ \\
\hline 1 & Тл-Бб & 1,60 & 31,2 & 93,0 & 1,075 & 0,822 & 1,057 & 1,8 & 159 \\
\hline 2 & Тл-Бб & 1,60 & 96,4 & 96,0 & 1,053 & 0,824 & 1,044 & 3,2 & 159 \\
\hline 3 & Тл-Бб & 1,60 & 37,5 & 97,4 & 1,062 & 0,822 & 1,056 & 0,8 & 159 \\
\hline
\end{tabular}

Таблица 2. Технологические показатели нагнетательных скважин

Table 2. Technological parameters of injection wells

\begin{tabular}{|c|c|c|c|c|c|c|c|}
\hline \multirow[b]{2}{*}{$\begin{array}{l}\text { Скв. } \\
\text { Well }\end{array}$} & \multirow[b]{2}{*}{$\begin{array}{c}\text { Пласт } \\
\text { Reservoir }\end{array}$} & \multirow[b]{2}{*}{$\begin{array}{l}\text { Тип воды } \\
\text { Water type }\end{array}$} & \multirow[b]{2}{*}{$\mathrm{P}_{\text {уст }}$} & $\begin{array}{c}\text { Фактический режим } \\
\text { Actual mode } \\
\end{array}$ & \multicolumn{3}{|c|}{$\begin{array}{l}\text { Намечаемый режим } \\
\text { Proposed mode }\end{array}$} \\
\hline & & & & $\begin{array}{c}\mathrm{Q}_{\text {потенц }}, \mathrm{m}^{3} / \text { сут } \\
\mathrm{Q}_{\text {pot }}, \mathrm{m}^{3} / \mathrm{d}\end{array}$ & $\mathrm{Q}, \mathrm{M}^{3} / \mathrm{cyT}$ & $\begin{array}{l}\text { Дни работы } \\
\text { Day of work }\end{array}$ & $\begin{array}{l}\text { Закачка } \\
\text { за месяц } \\
\text { Monthly } \\
\text { injection }\end{array}$ \\
\hline 4 & Бш-Срп+Тл-Бб & \multirow{2}{*}{ подтоварная } & 12 & 850 & \multirow{2}{*}{450} & 30 & 13500 \\
\hline 5 & D3f & & 12 & 1700 & & 30 & 13500 \\
\hline
\end{tabular}

Как видно из табл. 1, продукция скважин имеет высокую обводненность (более 90 \%). Такое высокое значение обеспечит эффективную сепарацию в стволе скважин. Дебит скважины по жидкости $165,1 \mathrm{~m}^{3} /$ сут, из них $159,3 \mathrm{~m}^{3} /$ сут воды, средняя обводненность $-96,5 \%$. Имеется значительный потенциал по закачке, что подтверждает возможность реализации технологии (табл. 2).

Скважина-сепаратор имеет следующие размеры: диаметр эксплуатационной колонны - 146 мм с толщиной стенки 8мм, в нее спускается две параллельных колонны НКТ с внешним диаметром 48 мм.

\section{Численный эксперимент процесса} скважинной сепарации

Проведено моделирование процесса кустовой сепарации гравитационным методом с использованием скважины в консервации с помощью программного продукта Aspen HYSYS [22]. В рамках задачи требовалось оценить расход воды через ЭЦН, при котором качество воды удовлетворяло СТП (количество нефтепродуктов до 28 мг/л, количество взвешенных веществ до $20 \mathrm{мг/л).}$

Результаты моделирования представлены в виде графика (рис. 3).

В соответствии с графиком и результатами моделирования в скважину-сепаратор необходимо установить насос с расходом в диапазоне до $120 \mathrm{~m}^{3} /$ сут и вести эксплуатацию с расходом до 119 м $/$ сут, чтобы качество воды соответствовало требуемым показателям воды для закачки в пласт.

В скважинном сепараторе выделяется так называемый полезный объем между точкой выхода эмуль- 
сии из НКТ-1 и входа в НКТ-2 (участок перемешивания эмульсии). Качество воды на входе в НКТ-2 должно быть выше стандарта предприятия (СТП) по содержанию нефтепродуктов и ТВЧ для закачки в пласт. В условиях гравитационного отстоя качество продукции зависит от времени, за которое из водной среды нефтяная фаза успеет отделиться и всплыть. Скорость всплытия должна быть больше или равна скорости опускания слоя отделившейся воды в скважине, вследствие откачки насосом. В процессе всплытия капли нефти коагулируют, образуя при этом более крупные капли, увеличивают линейный размер, что улучшает условия по разделению эмульсии согласно закону Стокса:

$$
\vartheta_{\mathrm{H}}=\frac{\mathrm{d}_{\mathrm{H}}^{2} \cdot\left(\rho_{\mathrm{B}}-\rho_{\mathrm{H}}\right) \cdot \mathrm{g}}{18 \cdot \mu_{\mathrm{B}}},
$$

где $\vartheta_{\text {н }}-$ скорость всплытия капель нефти в воде, м/с;

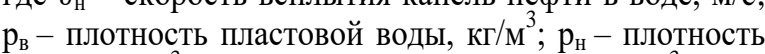
нефти, кг $/ \mathrm{m}^{3} ; \mathrm{d}_{\mathrm{H}}-$ диаметр капель воды, кг $/ \mathrm{m}^{3} ; \mu_{\mathrm{B}}-$ динамическая вязкость пластовой воды, Па·с.

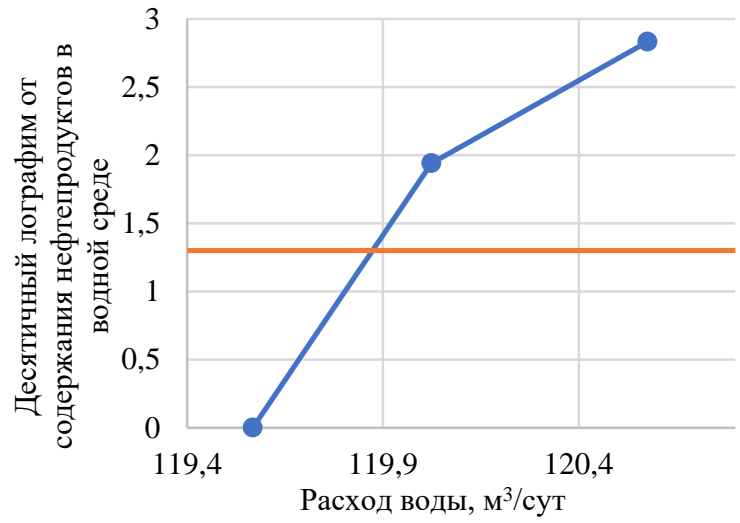

Рис. 3. Зависимость содержания нефтепродуктов от расхода водbl

Fig. 3. Dependence of oil content on water consumption

Скорость всплытия в соответствии с вышеописанным процессом увеличивается по мере подъема капли и ее укрупнения.

По данным лабораторных исследований для заданной эмульсии устанавливается зависимость содержания нефтепродуктов в воде от времени гравитационного отстоя (рис. 4).

Зная планируемую глубину спуска насоса и расход воды, определяется время сепарации $\Delta \mathrm{t}^{*}$ :

$$
\Delta \mathrm{t}^{*}=\frac{\mathrm{H}_{\text {нас }}-\mathrm{H}_{\text {вст }}-\Delta \mathrm{H}}{\vartheta_{\text {в Скв }}},
$$

где $\mathrm{H}_{\text {нас }}$ - глубина насоса, м; $\mathrm{H}_{\text {вст }}-$ глубина трубной вставки, м; $\Delta \mathrm{H}-$ запас глубины, м; $\vartheta_{\text {в скв }}-$ скорость оседания капель воды, м/с.

Скорость оседания капель воды находится как частное между расходом воды и площадью поперечного сечения, где происходит разделение. Параметр запас глубины вводится для полной уверенности, что вода достигла необходимого качества для использования в системе ППД. При этом полученное значение должно быть больше или равно некоему критическому значению времени, которое может быть определено в лабораторных исследованиях:

$$
\Delta \mathrm{t}^{*} \geq \Delta \mathrm{t}_{\text {кр }}
$$

где $\Delta \mathrm{t}_{\text {кр }}-$ критическое значение времени процесса сепарации, при котором выполняются требования СТП по содержанию нефтепродуктов.

Скважина-сепаратор имеет следующие размеры: диаметр эксплуатационной колонны - 146 мм с толщиной стенки 7,7 мм, в нее спускается две параллельных колонны НКТ с внешним диаметром 48 мм. Исходные данные для проектирования и моделирования технологии приведены в табл. 3.

Таблица 3. Исходные данные и результаты расчета nроиесcа cenapaūu

\begin{tabular}{|c|c|}
\hline Наименование/Name & $\begin{array}{l}\text { Зна- } \\
\text { чение } \\
\text { Value }\end{array}$ \\
\hline Расход воды, м $^{3} /$ сут; $\left(\mathrm{Q}_{\mathrm{B}}\right) /$ Water flow rate, $\mathrm{m}^{3} / \mathrm{d}$ & 120 \\
\hline $\begin{array}{l}\text { Скорость опускания слоя отделившейся воды, кото- } \\
\text { рая соответствует заданному расходу, м/с; ( } \vartheta_{\text {в скв) }} \\
\text { Rate of lowering the separated water layer, which corre- } \\
\text { sponds to the specified flow rate, } \mathrm{m} / \mathrm{s}\end{array}$ & 0,117 \\
\hline Глубина спуска насоса, м; $\mathrm{H}_{\text {нас }} /$ Pump setting depth, m & 1500 \\
\hline $\begin{array}{l}\text { Глубина спуска трубной вставки, м; } \mathrm{H}_{\text {вст }} \\
\text { Pipe insert descent depth, m }\end{array}$ & 100 \\
\hline Запас глубины, м; $\Delta$ H/Depth margin, m & 50 \\
\hline $\begin{array}{l}\text { Время процесса сепарации по рассматриваемому } \\
\text { объекту, мин } \\
\text { Separation time for the object under consideration, min }\end{array}$ & 192,3 \\
\hline
\end{tabular}

Table 3. Initial data and calculation results of separation

\section{Стендовые испытания}

Для расчета критического времени процесса сепарации разработан лабораторный стенд, имитирующий скважину, - полая труба длиной 1600 мм с внутренним диаметром 50 мм, с расположенными на ней шаровыми кранами для отбора проб с различных уровней. За счет гравитационного разделения эмульсии определялось содержание нефтепродуктов на различных уровнях и скорость их всплытия в воде при различных интервалах времени отстоя эмульсии.

По результатам лабораторных исследований построен график зависимости содержания нефтепродуктов от времени гравитационного отстоя эмульсии.

Из рис. 4 установлено критическое время гравитационного отстоя, при котором качество воды отвечает требованиям СТП. Для крана № 1 (соответствует нижней части стенда) время отстоя составляет 10 минут, для крана № 3 (соответствует средней части стенда) - 60 минут. Из расчета время процесса сепарации при заданных исходных данных составляет 192,3 минуты, что значительно больше критического значения времени $\Delta \mathrm{t}_{\mathrm{\kappa p}}=60$ минут (для крана № 3), и имеется значительный потенциал по расходу сброшенной воды из скважины. Отбор проб воды в средней и нижней части стенда обусловлен тем, что в указанных областях не накапливается нефтяная шапка и имеется свободный объем для всплытия дисперсной фазы (нефтепродуктов) в дисперсионной среде (воде). 


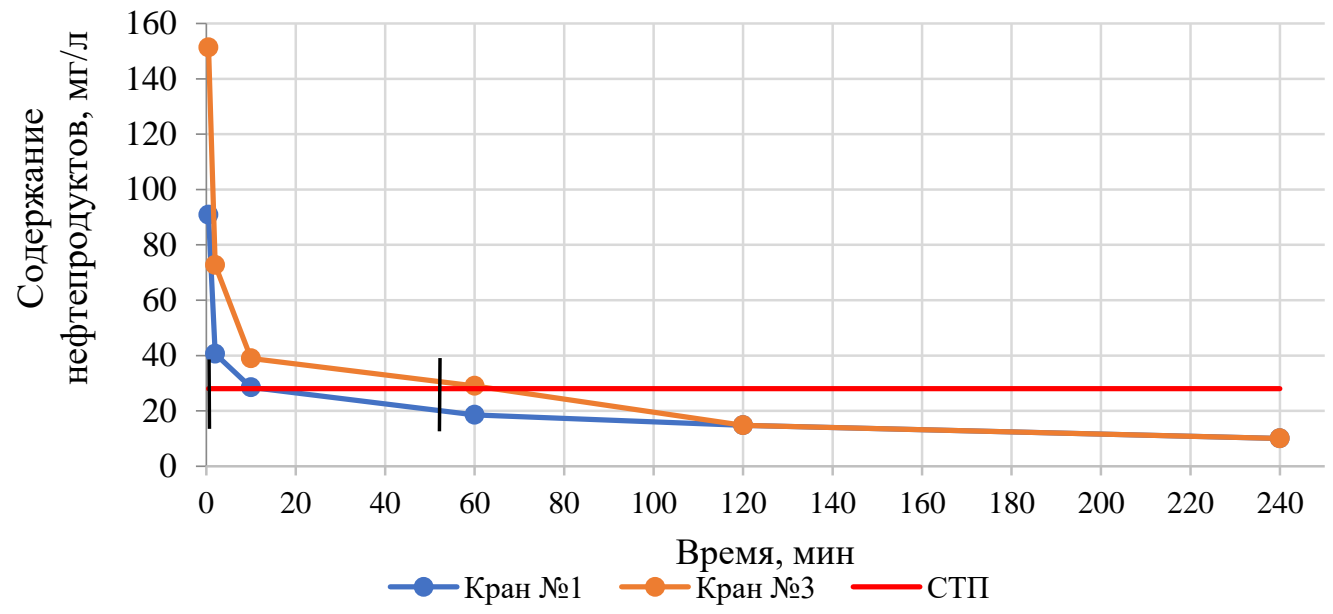

Pис. 4. Зависимость содержания нефтепродуктов от времени отстоя эмульсии

Fig. 4. Dependence of petroleum products content on emulsion settling time

\section{Оценка экономической эффективности}

Для расчета операционных затрат на транспортировку и подготовку добываемой жидкости определялись удельные значения затрачиваемых средств на 1 $\mathrm{M}^{3}$ по каждой статье затрат по следующей формуле:

$$
\delta=\frac{\mathrm{N} \cdot \mathrm{S}}{\mathrm{Q}} \mathrm{py}^{\mathrm{s}} / \mathrm{M}^{3}
$$

где $\mathrm{N}$ - количество затрачиваемой энергии или агента для подготовки или перекачки; $\mathrm{S}$ - стоимость энергии или агента; Q - количество жидкости, участвующей в процессе.

В общем случае затраты состоят из затрат на электроэнергию для перекачки (потребляемая насосами на дожимной насосной станции (ДНС), насосами на установке по подготовке и перекачке нефти (УППН) для внутренней перекачки жидкости), электроэнергию на нагрев газожидкостной смеси на печах и теплообменниках, электроэнергию, потребляемую высоконапорными насосами на блочной кустовой насосной станции (БКНС) для ППД, а также расходы на деэмульгатор.

В табл. 4 представлены значения удельных затрат электроэнергии и агента предприятием за 2019 г.

Используя рассчитанные удельные расходы для 1 $\mathrm{M}^{3}$ жидкости, определим количество средств, которые предприятие будет экономить после реализации кустовой сепарации в год.

До реализации кустовой сепарации затраты на транспортировку и подготовку составляли:

$$
\mathrm{S}_{\text {СиП до }}=\mathrm{Q}_{\text {ж }} \cdot \delta \cdot 365 \text {, }
$$

где $\mathrm{Q}_{ж}$ - общее количество добываемой жидкости; $\delta$ удельные затраты на транспортировку и подготовку.

Затраты энергии насосами на КНС для обратной транспортировки воды и создания давления для ППД составляли:

$$
\mathrm{S}_{\text {Ппд до }}=\mathrm{Q}_{\text {зак }} \cdot \gamma_{\text {до }} \cdot 365 \text {. }
$$

Общие затраты:

$$
S_{\text {до }}=S_{\text {СиП до }}+S_{\text {Ппд до }} \text { руб } / \text { год. }
$$

\begin{tabular}{|c|c|c|}
\hline \multicolumn{2}{|c|}{ Пункт затрат/Cost point } & $\begin{array}{l}\text { Удельные } \\
\text { затраты, } \\
\text { p./m³ } \\
\text { Unit costs, } \\
\text { rub/ m }{ }^{3} \\
\end{array}$ \\
\hline \multicolumn{2}{|c|}{$\begin{array}{l}\text { для транспортировки до УППН } \\
\text { for transportation to the crude oil treating plant } \\
\text { (COTP) }\end{array}$} & 17,68 \\
\hline \multicolumn{2}{|c|}{$\begin{array}{l}\text { для внутренней перекачки на УППН } \\
\text { for internal pumping to the СОТР }\end{array}$} & 3,84 \\
\hline \multicolumn{2}{|c|}{$\begin{array}{l}\text { для нагрева газожидкостной смеси (ГЖС) на } \\
\text { УППН - печи } \\
\text { for heating the gas-liquid mixture on the СОТР - } \\
\text { furnace }\end{array}$} & 1,53 \\
\hline \multicolumn{2}{|c|}{$\begin{array}{l}\text { для нагрева ГЖС на УППН - теплообменники } \\
\text { for heating a gas-liquid mixture on the СОТР - heat } \\
\text { exchangers }\end{array}$} & 2,30 \\
\hline \multirow{2}{*}{$\begin{array}{l}\text { Энергия, для систе- } \\
\text { мы ППД } \\
\text { Energy, for maintain } \\
\text { formation pressure } \\
\text { (MFP) system }\end{array}$} & $\begin{array}{l}\text { БКНС } \\
\text { Water injection station } \\
\text { (WIS) }\end{array}$ & 45,29 \\
\hline & $\begin{array}{l}\text { при кустовой сепарации } \\
\text { for cluster separation }\end{array}$ & 34,85 \\
\hline \multicolumn{2}{|c|}{$\begin{array}{l}\text { Количество добавляемого деэмульгатора } \\
\text { Number of demulsifiers to add }\end{array}$} & 7,24 \\
\hline \multicolumn{2}{|c|}{$\begin{array}{l}\text { Общие затраты на сбор и подготовку добываемой } \\
\text { жидкости } \\
\text { Total costs for collecting and preparing the extracted } \\
\text { liquid }\end{array}$} & 32,59 \\
\hline
\end{tabular}

Таблица 4. Количество затрачиваемой энергии (за год)

Table 4. Amount of energy consumed (per year)

При суточной добыче жидкости $\mathrm{Q}_{\text {ж }}$ и добыче воды $\mathrm{Q}_{\text {в }}$ на УППН будет транспортироваться:

$$
Q_{\text {трансп }}=Q_{ж}-Q_{\text {в }} \frac{\mathrm{M}^{3}}{\text { сут }} \text {. }
$$

После реализации кустовой сепарации затраты на транспортировку и подготовку будут составлять:

$$
\mathrm{S}_{\text {СиП после }}=\mathrm{Q}_{\text {трансп }} \cdot \delta \cdot 365 \text {. }
$$

Затраты энергии для ППД после реализации кустовой сепарации будут разделяться на часть, затрачиваемую на КНС ( $\left.W_{\text {КНC }}\right)$, и на часть, потребляемую насосом $\left(W_{\text {кс }}\right)$, установленным в скважине для ППД. Общие затраты на ППД после реализации будут составлять:

$$
S_{\text {Ппд после }}=\left(W_{\text {КС }} \cdot Q_{\text {в }} \cdot \gamma_{\text {после }}+W_{\text {КНС }} \cdot Q_{\text {в }} \cdot \gamma_{\text {до }}\right) \cdot 365 .
$$


Общие затраты после реализации составят:

$$
S_{\text {после }}=S_{\text {СиП после }}+S_{\text {Ппд после }} \text {. }
$$

Общая экономия составит:

$$
S_{\text {экон }}=S_{\text {до }}-S_{\text {после }} \text {. }
$$

Все численные значения представлены в табл. 5.

Таблица 5. Результаты расчета экономии средств, mblc. p./2od

Table 5. Results of calculation of savings, thousands

\begin{tabular}{|c|c|}
\hline Наименование затрат/Cost name & $\begin{array}{l}\text { Величи- } \\
\text { на затрат } \\
\text { Cost } \\
\text { amount }\end{array}$ \\
\hline \multicolumn{2}{|l|}{$\begin{array}{l}\text { До реализации кустовой сепарации } \\
\text { Before implementing cluster separation }\end{array}$} \\
\hline $\begin{array}{l}\text { Затраты на сбор и подготовку ГЖС } \\
\text { Costs for collecting and preparing a gas-liquid mixture }\end{array}$ & 1777,2 \\
\hline Затраты на ППД /Costs for MFP & 2363,5 \\
\hline Общие затраты/Total input & 4140,7 \\
\hline \multicolumn{2}{|l|}{$\begin{array}{c}\text { После реализации кустовой сепарации } \\
\text { After implementation of the group separation }\end{array}$} \\
\hline $\begin{array}{l}\text { Затраты на сбор и подготовку ГЖС } \\
\text { Costs for collecting and preparing a gas-liquid mixture }\end{array}$ & 586,6 \\
\hline $\begin{array}{l}\text { Затраты на ППД (в том числе на устьевое оборудо- } \\
\text { вание технологии кустовой сепарации) } \\
\text { Costs for MFP (including wellhead equipment for } \\
\text { cluster separation technology) }\end{array}$ & 1982,2 \\
\hline Общие затраты/Total input & 2568,8 \\
\hline $\begin{array}{l}\text { Общая экономия средств за год } \\
\text { Total cost savings for the year }\end{array}$ & 1571,9 \\
\hline
\end{tabular}
rublyear

Величина разовых затрат для реализации проекта, а именно на изготовление блочной установки кустовой сепарации и монтажа трубопроводной обвязки, составит 3 млн руб. С учётом экономии средств за год рассчитаем срок окупаемости без учета ремонтных работ высоконапорного трубопровода и восстановления работоспособности 1 раз в 10 лет:

\section{СПИСОК ЛИТЕРАТУРЫ}

1. Султанаева А.Р. Обезвоживание нефти с последующим применением воды для закачки в пласт // Проблемы науки. 2018. - № 4. - С. 56-59.

2. Кусов Г.В., Савенок О.В. Реконструкция Южно-Ягунского нефтяного месторождения // Булатовские чтения. - 2017. № 2. - С. 133-141.

3. Хафизов А.Р., Галиуллин Р.Ш., Фаткуллин А.А. О внедрении новых технологий и концепции измерений в системах сбора и подготовки продукции нефтяных скважин // Нефтегазовое дело. - 2011. - № 6. - С. 295-306.

4. Обоснование возможности применения технологии кустового сброса воды на Ново-Киевском месторождении / Г.К. Борисов, В.Ф. Шаякберов, М.Х. Газимов, К.Б. Борисов, А.В. Мостобоев // Нефтепромысловое дело. - 2011. - № 12. - С. 46-51.

5. Иванов В.А., Кудашев С.В. Система сбора продукции высокообводнённых скважин и утилизации пластовой воды // Нефтепромысловое дело. - 2012. - № 2. - С. 44-48.

6. Abdel-Fattah A.I. Acoustic downhole oil/water/fines separation (ADOWFs) // SPE Production and Operations. - 2018. - V. 33. P. 829-836.

7. A novel oil-water separator design and its performance prediction / Q. Zeng, Z. Wang, X. Wang, Y. Zhao, X. Guo // Journal of Petroleum Science and Engineering. - 2016. - V. 145. - P. 83-94.

8. Zhao C., Sun H., Li Z. Structural optimization of downhole oilwater separator // Journal of Petroleum Science and Engineering. 2017. - V. 148. - P. 115-126.

$$
\mathrm{CO}=\frac{C A P E X}{S_{\text {экон }}}=\frac{3}{1572}=1,91 \text { лет, }
$$

где СО - срок окупаемости; САРЕХ - разовые затраты для реализации проекта.

Таким образом, срок окупаемости проекта составляет менее 2 лет.

\section{Заключение}

Представлены результаты аналитического расчета процесса сепарации, результаты стендовых испытаний, а также результаты моделирования в программном продукте Aspen Hysys. По полученным результатам определены параметры работы установки внутрискважинной сепарации, при которых достигаются все требования по показателям воды для закачки в пласт. Дополнительно были проведены лабораторные исследования на содержание в воде ТВЧ, по результатам которых выявлена необходимость в фильтрационной установке.

Представленная технология позволяет достичь сокращения затрат на транспорт и подготовку объема балласта (подтоварной воды), то есть сократить расходы реагентов для обеспечения процесса (деэмульгатора, ингибитора коррозии).

Благодаря снижению количества перекачиваемой жидкости уменьшается нагрузка на ДНС и УППН и повышается качество подготовки продукта. Предложенная технология позволяет децентрализовать подготовку воды, тем самым снизив ее затраты на транспортировку от КНС до нагнетательной скважины, а также позволяет уменьшить давления в системе сбора за счет снижения вязкости водонефтяной эмульсии и повышения температуры потока.

Исследование проведено при финансовой поддержке Минобрнауки России в рамках реализации программь деятельности научно-образовательного центра мирового уровня «Рациональное недропользование».

9. Progress and prospect of downhole cyclone oil-water separation with single-well injection-production technology / H. Liu, Y. Gao, X. Pei, G. Zheng, L. Zheng // Shiyou Xuebao/Acta Petrolei Sinica. - 2018. - V. 39. - P. 463-471.

10. Downhole oil-water separation moves into high gear / B.R. Peachey, S.C. Solanki, T.A. Zahacy, K. Piers // Journal of Canadian Petroleum Technology. - 1998. - V. 37. - P. 31-41.

11. Application of downhole oil/water separation systems in the alliance field / C.M. Matthews, R. Chachula, B.R. Peachey, S.C. Solanki // Proceedings of the 1996 3rd International Conference on Health, Safety and Environment in Oil and Gas Exploration and Production. P. 2 (of 2). - New Orleans, 1996. P. 453-462.

12. Study on the oil/water separation performance of a superhydrophobic copper mesh under downhole conditions / Y. Lu, Z. Li, G. Hailu, D. Xu, H. Wu, W. Kang // Journal of industrial and engineering chemistry. - 2019. - V. 72. - P. 310-318.

13. Bowers B.E., Brownlee R.F., Schrenkel P.J. Development of a downhole oil/water separation and reinjection system for offshore application // SPE Production and Facilities. - 2000. - V. 15. P. 115-122.

14. Шаякберов В.Ф. Скважинная установка сброса воды для кустов скважин // Оборудование и технологии для нефтегазового комплекса. - 2009. - № 3. - С. 15-17.

15. Установка для внутрискважинного разделения нефти от воды: пат. Рос. Федерация, № 25319776, заявл. 20.11.2012; опубл. 27.10.2014. Бюл. № 30. 
16. Установка для внутрискважинной сепарации водогазонефтяной смеси от воды: пат. Рос. Федерация, № 2483211, заявл. 05.07.2012; опубл. 27.05.2013. Бюл. № 15 .

17. Устройство для добычи нефти с внутрискважинной сепарацией: пат. Рос. Федерация, № 2575856, заявл. 19.03.2014; опубл. 20.02.2016. Бюл. № 5.

18. Сепарационная установка: пат. Рос. Федерация, № 2252312, заявл. 18.04.2003; опубл. 20.05.2005. Бюл. № 14.

19. Способ кустового сброса и утилизации попутно добываемой воды: пат. Рос. Федерация, № 2588234, заявл. 29.04.2015; опубл. 27.06.2016. Бюл. № 18.

20. Комплексная кустовая установка обезвоживания нефти, очистки и утилизации попутно добываемой пластовой воды: пат. Рос. Федерация, № 2411055, заявл. 18.08.2009; опубл. 10.02.2011. Бюл. № 4 .

21. Голубев И.А. Пути и решения очистки промысловых вод для системы поддержания пластового давления // Нефтегазовое дело. - 2013. - № 3. - С. 87-96.

22. Силичев М.А., Жигарев Д.Б. Моделирование процесса кустовой сепарации скважинной продукции // Проблемы разработки месторождений углеводородных и рудных полезных ископаемых. - 2019. - № 1. - С. 200-202.

Поступила 23.09.2020 2.

\section{Информация об авторах}

Лекомцев A.B., кандидат технических наук, доцент кафедры нефтегазовых технологий Пермского национального исследовательского политехнического университета.

Дерендяев К.A., бакалавр Пермского национального исследовательского политехнического университета. Бурцев $\boldsymbol{A}$. C., бакалавр Пермского национального исследовательского политехнического университета.

Степаненко И.Б., бакалавр Пермского национального исследовательского политехнического университета. Жигарев Д.Б., бакалавр Пермского национального исследовательского политехнического университета. 
UDC 622.276 .58

\title{
UTILIZATION OF BALLAST WATER PRODUCED ALONG THE WAY USING THE TECHNOLOGY OF WELL SEPARATION OF OIL-WATER EMULSIONS
}

\author{
Alexander V. Lekomtsev 1 , \\ alex.lekomtsev@mail.ru
}

Konstantin A. Derendyaev 1 , k.derendyaev@yandex.ru

Andrey S. Burtsev ${ }^{1}$, andrey.burtsev97@gmail.com

Ivan B. Stepanenko1, stepanenko2403@gmail.com

Daniel B. Zhigarev ${ }^{1}$, zhigarev.daniil@mail.ru

1 Perm National Research Polytechnic University, 29, Komsomolskiy avenue, Perm, 614990, Russia.

The relevance. One of the main problems of the oil and gas industry in the field of oil and gas production is the production of large volumes of ballast water. The average multiplicity of pumped water to oil can be 4:1 or more. On the territory of the Perm region, this problem is particularly urgent, since many fields are at the $3^{\text {rd }}$ and $4^{\text {th }}$ stages of development and require the introduction of new technologies for more profitable oil production. Due to the pumping of large volumes of liquid, the equipment is worn faster and additional energy costs for its use appear. In this regard, the introduction of technology for well and cluster separation of oil-water emulsion is one of the most effective ways to solve the production problem, by decentralizing the system for collecting and preparing well products.

Objects: well bushes with an average water cut of 65-70\% or more.

Methods: simulation of the cluster separation process in Aspen HYSYS; laboratory studies on the created layout that simulates a well.

Results. This paper presents the technology of cluster separation of well products for oil and water with further use of simultaneously produced water in the system of reservoir pressure maintenance. The technological scheme of the installation is presented. Laboratory tests were carried out and the optimal parameters of its operation were identified. The technical and economic assessment of the technology implementation and justified technical solutions are given.

Key words:

Production fluid preparation, downhole segregation, ballast water, water-oil emulsion, water release.

This research was carried out with the financial support of the Ministry of Science and Higher Education of the Russian Federation in the framework of the program of activities of the Perm Scientific and Educational Center «Rational Subsoil Use».

\section{REFERENCES}

1. Sultanayeva A.R. Obezvozhivanie nefti s posleduyushchim primeneniem vody dlya zakachki v plast [Dewatering of oil with subsequent application of water for injection into the reservoir]. Problemy nauki, 2018, no. 4, pp. 56-59.

2. Kusov G.V., Savenok O.V. Reconstruction of the YuzhnoYagunskoye oil field. Readings name of A.I. Bulatov, 2017, no. 2 pp. 133-141. In Rus.

3. Hafizov A.R., Galiullin R.Sh., Fatkullin A.A. Implementing new technologies and measurement concepts in gathering systems and well production processing. Oil and Gas Business, 2011, no. 6, pp. 295-306. In Rus.

4. Boreskov G.K., Shayakberov V.F., Gazizov M.Kh., Borisov K.B., Mastobaev A.V. Obosnovanie vozmozhnosti primeneniya tekhnologii kustovogo sbrosa vody na Novo-Kievskom mestorozhdenii [Justification of the possibility of using the technology of cluster water discharge at the Novokievskoe field]. Neftepromyslovoe delo, 2011, no. 12, pp. 46-51.

5. Ivanov V.A., Kudashev S.V. Sistema sbora produktsii vysokoobvodnennykh skvazhin i utilizatsii plastovoy vody [System for collecting products from high-water wells and utilization of reservoir water]. Neftepromyslovoe delo, 2012, no. 2, pp. 44-48.

6. Abdel-Fattah A.I. Acoustic downhole oil/water/fines separation (ADOWFs). SPE Production and Operations, 2018, vol. 33, pp. 829-836.
7. Zeng Q., Wang Z., Wang X., Zhao Y., Guo X. A novel oil-water separator design and its performance prediction. Journal of Petroleum Science and Engineering, 2016, vol. 145, pp. 83-94.

8. Zhao C., Sun H., Li Z. Structural optimization of downhole oilwater separator. Journal of Petroleum Science and Engineering, 2017, vol. 148, pp. 115-126.

9. Liu H., Gao Y., Pei X., Zheng G., Zheng L. Progress and prospect of downhole cyclone oil-water separation with single-well injection-production technology. Shiyou Xuebao/Acta Petrolei Sinica, 2018, vol. 39, pp. 463-471.

10. Peachey B.R., Solanki S.C., Zahacy T.A., Piers K. Downhole oilwater separation moves into high gear. Journal of Canadian Petroleum Technology, 1998, vol. 37, pp. 31-41.

11. Matthews C.M., Chachula R., Peachey B.R., Solanki S.C. Application of downhole oil/water separation systems in the alliance field. Proceedings of the $19963^{\text {rd }}$ International Conference on Health, Safety and Environment in Oil and Gas Exploration and Production. P. 2 (of 2). New Orleans, 1996. pp. 453-462.

12. Lu Y., Li Z., Hailu G., Xu D., Wu H., Kang W. Study on the oil/water separation performance of a super-hydrophobic copper mesh under downhole conditions. Journal of industrial and engineering chemistry, 2019, vol. 72, pp. 310-318.

13. Bowers B.E., Brownlee R.F., Schrenkel P.J. Development of a downhole oil/water separation and reinjection system for offshore application. SPE Production and Facilities, 2000, vol. 15, pp. 115-122. 
14. Shayakberov V.F. Skvazhinnaya ustanovka sbrosa vody dlya kustov skvazhin [Downhole water discharge plant for well bushes] Oborudovanie i tekhnologii dlya neftegazovogo kompleksa, 2009. no. 3, pp. $15-17$.

15. Rakhmanov A.R., Ozheredov E.V., Akhmadiev R.N., Latfullin R.R., Dzhafarov M.A. Ustanovka dlya vnutriskvazhinnogo razdeleniya nefti ot vody [Installation for downhole separation of oil from water]. Patent RF, no. 25319776, 2014

16. Ibragimov N.G., Rakhmanov A.R., Taziev M.Z., Ozheredov E.V., Dzhafarov M.A. Ustanovka dlya vnutriskvazhinnoy separatsii vodogazoneftyanoy smesi ot vody [Installation for downhole separation of water-gas- oil mixture from water]. Patent RF, no. 2483211,2013

17. Galay M.I., Demyanenko N.A., Mulitsa S.I., Tretyakov D.L., Serebrennikov A.V., Manuylo V.S., Tokarev V.V. Ustroystvo dlya dobychi nefti s vnutriskvazhinnoy separatsiey [Device for oil production with downhole separation]. Patent RF, no. 2575856, 2016.

18. Ramazanov N.R., Mingulov Sh.G., Gataullin Sh.G., Gepshteyn F.S., Shayakberov V.F Separatsionnaya ustanovka [Separation unit]. Patent RF, no. 2252312, 2005.
19. Umantsev A.A., Gilaev A.G., Sakhnov R.V., Demenin D.M., Antonov A.A., Shayakberov V.F. Sposob kustovogo sbrosa i utilizatsii poputno dobyvaemoy vody [Method of cluster discharge and utilization of simultaneously extracted water]. Patent RF, no. 2588234, 2015.

20. Latypov A.R., Mindeev A.N., Golubev V.F., Golubev M.V., Shaydullin F.D., Kashtanova L.E., Yukov A.Yu., Bedrin V.G. Kompleksnaya kustovaya ustanovka obezvozhivaniya nefti, ochistki $i$ utilizatsii poputno dobyvaemoy plastovoy vody [Integrated cluster installation oil dehydration, treatment and disposal of produced formation water]. Patent RF, no. 2411055, 2011.

21. Golubev I.A. Ways and solutions of industrial water treatment for reservoir pressure maintenance system. Oil and Gas Engineering, 2013, no. 3, pp. 87-96. In Rus.

22. Silichev M.A., Zhigarev D.B. Modelirovanie protsessa kustovoy separatsii skvazhinnoy produktsii [Modeling of the process of cluster separation of borehole products]. Problemy razrabotki mestorozhdeniy uglevodorodnykh $i$ rudnykh poleznykh iskopaemykh, 2019, no. 1, pp. 200-202.

\section{Information abour rhe authors}

Alexander V. Lekomtsev, Cand. Sc., associate professor, Perm National Research Polytechnic University.

Konstantin A. Derendyaev, student, Perm National Research Polytechnic University.

Andrey S. Burtsev, student, Perm National Research Polytechnic University.

Ivan B. Stepanenko, student, Perm National Research Polytechnic University.

Daniel B. Zhigarev, student, Perm National Research Polytechnic University. 